\title{
Finalizing a measurement framework for the burden of treatment in complex patients with chronic conditions
}

This article was published in the following Dove Press journal:

Patient Related Outcome Measures

27 March 2015

Number of times this article has been viewed

\author{
David T Eton ${ }^{1,2}$ \\ Jennifer L Ridgeway ${ }^{1,2}$ \\ Jason S Egginton ${ }^{1,2}$ \\ Kristina Tiedje ${ }^{3}$ \\ Mark Linzer ${ }^{4,5}$ \\ Deborah H Boehm ${ }^{4}$ \\ Sara Poplau 6 \\ Djenane Ramalho de \\ Oliveira $^{7}$ \\ Laura Odell ${ }^{8}$ \\ Victor M Montori ${ }^{1,9}$ \\ Carl R May ${ }^{10}$ \\ Roger T Anderson"
}

'Division of Health Care Policy and Research, Department of Health Sciences Research, Mayo Clinic, Rochester, MN, USA; ${ }^{2}$ Robert D and Patricia E Kern Center for the Science of Health Care Delivery, Mayo Clinic, Rochester, MN, USA; ${ }^{3}$ Department of Sociology and Anthropology, Université Lumière Lyon 2, Lyon, France; ${ }^{4}$ Division of General Internal Medicine, Hennepin County Medical

Center, Minneapolis, MN, USA; ${ }^{5}$ University of Minnesota Medical School, University of Minnesota, Minneapolis, MN, USA;

${ }^{6}$ Minneapolis Medical Research Foundation, Minneapolis, MN, USA; ${ }^{7}$ Department of Social Pharmacy, Universidade Federal de Minas Gerais, Belo Horizonte, Minas Gerais, Brazil; ${ }^{8}$ Pharmacy Services, Mayo Clinic, Rochester, MN, USA; ${ }^{9}$ Knowledge and Evaluation Research Unit, Mayo Clinic, Rochester, MN, USA; ${ }^{10} \mathrm{Faculty}$ of Health Sciences and NIHR CLAHRC Wessex, University of Southampton, Southampton, UK; "School of Medicine, University of Virginia, Charlottesville, VA, USA

Correspondence: David T Eton Division of Health Care Policy and Research, Department of Health

Sciences Research, Mayo Clinic, 200 First Street SW, Rochester, MN 55905, USA

Tel +I 507293 I 353

Fax + I 507284 I73I

Email eton.david@mayo.edu
Purpose: The workload of health care and its impact on patient functioning and well-being is known as treatment burden. The purpose of this study was to finalize a conceptual framework of treatment burden that will be used to inform a new patient-reported measure of this construct. Patients and methods: Semi-structured interviews were conducted with 50 chronically ill patients from a large academic medical center $(n=32)$ and an urban safety-net hospital $(n=18)$. We coded themes identifying treatment burden, with the themes harmonized through discussion between multiple coders. Four focus groups, each with five to eight participants with chronic illness, were subsequently held to confirm the thematic structure that emerged from the interviews.

Results: Most interviewed patients (98\%) were coping with multiple chronic conditions. A preliminary conceptual framework using data from the first 32 interviews was evaluated and was modified using narrative data from 18 additional interviews with a racially and socioeconomically diverse sample of patients. The final framework features three overarching themes with associated subthemes. These themes included: 1) work patients must do to care for their health (eg, taking medications, keeping medical appointments, monitoring health); 2) challenges/ stressors that exacerbate perceived burden (eg, financial, interpersonal, provider obstacles); and 3) impacts of burden (eg, role limitations, mental exhaustion). All themes and subthemes were subsequently confirmed in focus groups.

Conclusion: The final conceptual framework can be used as a foundation for building a patient self-report measure to systematically study treatment burden for research and analytical purposes, as well as to promote meaningful clinic-based dialogue between patients and providers about the challenges inherent in maintaining complex self-management of health.

Keywords: treatment burden, conceptual framework, adherence, questionnaire, self-management, multi-morbidity

\section{Introduction}

Excessive burden of treatment and self-management of chronic conditions is a vexing problem for health care providers and patients. Patients burdened by the volume, complexity, and difficulty of prescribed treatments and required self-care can struggle with adherence to their medical regimens. ${ }^{1-5}$ Low adherence to necessary care can result in more hospital admissions and worse clinical outcomes, including higher mortality. ${ }^{6,7}$ Perceived burden also exacts a personal toll on patients, as it is associated with poorer quality of life. ${ }^{8-11}$ Over the past few years, our research team has sought to better understand precisely what "burden of treatment" means to patients, especially those coping with multiple chronic conditions (MCCs). People with MCCs are particularly vulnerable to feeling burdened, as they are frequently asked by providers to engage in an array of self-care activities in order to maintain health at an optimal level. ${ }^{12}$ 
A critical element of our exploration of treatment burden is articulation of a general conceptual understanding, one that might inform the development of a patient-reported measure (PRM). Currently, there is a paucity of available means for assessing the many aspects of treatment burden in the MCC population, including no comprehensive, multi-domain measure. Existing measures tend to target specific diseases, ${ }^{10,13,14}$ treatment modalities, ${ }^{15-17}$ or circumscribed aspects of burden like perceived task difficulty. ${ }^{9}$ A comprehensive understanding, one not restricted to the context of a single disease or treatment regimen, is needed to fully comprehend how treatment burden is experienced by the person with MCCs and to ultimately inform clinicians how to intervene to reduce it.

To fill these gaps and to provide the foundation for a novel, PRM of treatment burden, we recently began development of a conceptual framework of treatment burden. Initially, we interviewed 32 patients seeking medication therapy management support services at the Mayo Clinic (Rochester, MN, USA) to construct a preliminary version of the framework. A full description of the methods and findings of these initial interviews are reported in Eton et al. ${ }^{18}$ The framework was considered preliminary, as it was derived using data from a single center and therapeutic program, and it relied on a single form of qualitative inquiry, the semi-structured interview. To enhance sample diversity and to ensure adequate representation of key concepts, we added a second site, the Hennepin County Medical Center (HCMC) in Minneapolis, Minnesota. The HCMC is Minnesota's largest safety-net hospital, providing care for many low-income and vulnerable persons. Furthermore, to triangulate and confirm results with a different yet complementary qualitative method, we conducted focus groups with diabetic, heart failure, and kidney failure patients at both research sites. Combining results of semistructured interviews and focus groups has been advocated when constructing a conceptual framework for a PRM. ${ }^{19}$ In this report, we build on the findings of our earlier report, ${ }^{18}$ identify modifications to the preliminary framework based on the new data obtained, and present a final version of a conceptual measurement framework of treatment burden. Data collected in these same interviews and focus groups have also been used in a recent complementary analysis to identify factors that may lessen treatment burden. ${ }^{20}$

\section{Materials and methods}

\section{Participants and settings}

Qualitative interviews and focus groups were conducted at the Mayo Clinic and the HCMC (Minneapolis, MN, USA). The Mayo Clinic is a large integrated practice providing comprehensive patient care in a variety of specialties. The HCMC is Minnesota's largest safety-net hospital and ambulatory care clinic system. Patients from both sites were needed to obtain sufficient variability in patient experience.

\section{Procedure}

\section{Qualitative interviews}

We sampled patients who could reasonably be assumed to be at risk of experiencing at least some treatment burden, namely those with MCCs involved with a complex regimen of medical self-care. Complex self-care was indicated by one or more of the following: polypharmacy, required health-status monitoring (eg, checking blood sugar), provider-recommended diet and/or exercise regimens, and/or other self-treatments (eg, injections, inhalers, breathing machines). Patients meeting these criteria were recruited from the Mayo Clinic's pharmacist-led medication therapy management program and from the HCMC's primary care outpatient clinic. Eligible Mayo Clinic patients were identified by the medication therapy management program coordinator (LO), and were then contacted by phone by a research assistant to arrange the interview. HCMC patients were recruited in the outpatient clinic by a study coordinator (DB or SP), who assessed eligibility, consented the patient, and scheduled the interview.

In-person interviews were conducted with Mayo Clinic patients from January 2010 through October 2011 and with HCMC patients from December 2012 through January 2013. One of three experienced interviewers (DE, JE, or JR) conducted the interview. The original interview guide can be found in Eton et al. ${ }^{18}$ Patients were queried about their medical conditions, how they care for them, the impact of medical self-care on their daily life, difficulties accomplishing selfcare, and factors that may alleviate treatment and self-care burden. Basic descriptive information about the patient was collected at the end of each interview. Most of the interviews (96\%) lasted less than 90 minutes (median $=46$ minutes). Interviews were recorded and later transcribed to facilitate analysis. Patients received US\$50 compensation for participating (cash or gift card). Conduct of these interviews was approved by the Institutional Review Boards overseeing research activities at the Mayo Clinic and the HCMC. All patients provided written informed consent and authorized the use and disclosure of their health information.

\section{Focus groups}

Following the interviews, a series of patient focus groups were scheduled to test the content representativeness (ie, content validity) of the conceptual framework derived from 
the interview data. Mayo Clinic patients were recruited through regular meetings of two patient advisory groups, one in diabetes and the other in heart failure. HCMC patients were recruited from cardiology and renal failure clinics. These conditions were targeted because they can involve considerable and long-term self-management on the part of patients. ${ }^{10,21,22}$

Four focus groups were conducted between March and May of 2013 (two at the Mayo Clinic, two at the HCMC). They were led by an experienced facilitator (KT) with three other team members (DE, JE, and JR) present to assist and take notes. The topic guide used by the facilitator was based on the conceptual framework of treatment burden that emerged from the qualitative interviews. Participants were asked to describe the work that they do to care for their health, the impact that this work has on their daily life and well-being, strategies that they use to help manage the work, and challenges that make the work more difficult to accomplish. The facilitator probed to elicit feedback on themes and subthemes of the conceptual framework, and to uncover any new (un-represented) issues. Demographic information was collected from chart reviews or through direct patient query. Patients received US\$75 compensation for participating in a group (cash or gift card). Institutional Review Boards at both institutions approved the research, and all participants provided written consent.

\section{Data analysis}

As described in Eton et al, ${ }^{18}$ framework analysis ${ }^{23}$ was used on the initial Mayo Clinic interviews to identify thematic patterns in the data and to derive the preliminary conceptual framework of treatment burden. The preliminary framework (Figure 1) was next applied to the narrative transcripts from the subsequent HCMC interviews. Three study team members (DE, JR, and JE) independently reviewed and coded these transcripts, subsequently meeting to discuss each one and to arrive at a consensus on coded text. NVivo software (Version 10; QSR International Pty Ltd, Melbourne, Australia) was used to help organize the narrative data. For issues that were not identified by codes in the working (preliminary) framework, discussion ensued, and consensus was reached to either modify an existing code or to add a new code. After coding of all interviews, a final review was done, and the conceptual framework was modified accordingly.

Focus group data were used to 1) test the fitness of the original conceptual framework arising from the interviews; and 2) clarify any new issues not represented in the current version of the framework. This assessment was based upon an analysis of field notes and audio files obtained from the groups. ${ }^{24}$ The facilitator (KT) and three study team members (DE, JE, and JR) took detailed notes and immediately debriefed findings after each group session. Upon completion of the first two focus group meetings, top-line reports

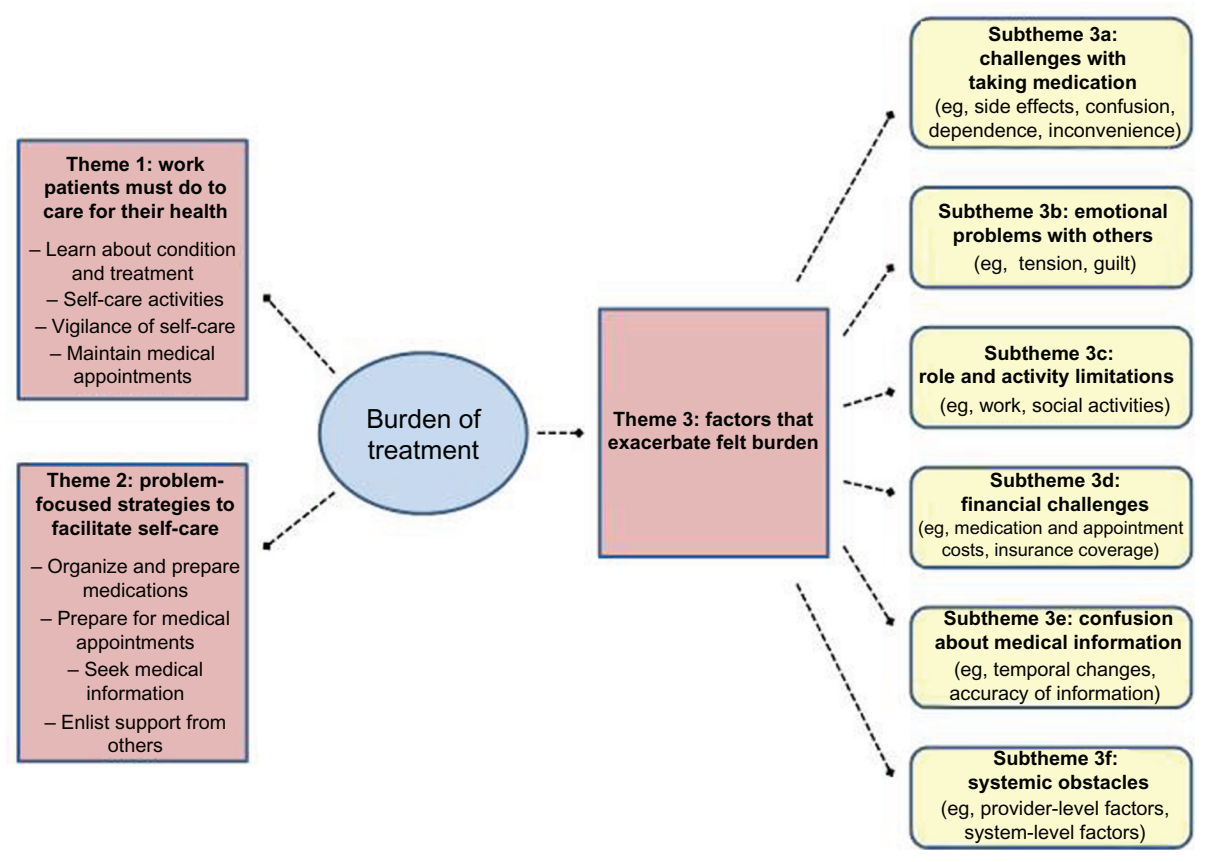

Figure I A preliminary conceptual measurement framework of burden of treatment.

Note: Copyright (C) 2012. Dove Medical Press. Reproduced from Eton DT, Ramalho de Oliveira D, Egginton JS, et al. Building a measurement framework of burden of treatment in complex patients with chronic conditions: a qualitative study. Patient Related Outcome Measures. 2012:3 39-49. ${ }^{18}$ 
(preliminary reports produced quickly) were distributed to two clinical members of the study team (DB and ML) for review and feedback. ${ }^{24}$ After completion of all four focus group sessions, two team members (DE and JR) compiled the data into a saturation grid that outlined the themes discussed in each group. The grid was also used to refine themes with overlapping or divergent content. KT and JE reviewed this report and provided feedback. This process resulted in a final conceptual framework of treatment burden.

\section{Results}

\section{Patient characteristics}

Thirty-two Mayo Clinic and $18 \mathrm{HCMC}$ patients were interviewed for this study. Descriptive characteristics of these patients appear in Table 1. The table is reprinted from our previous report of factors that may lessen treatment burden, ${ }^{20}$ a report featuring a complementary analysis of data from the same set of patient interviews. In brief, Mayo Clinic participants were slightly older, more formally educated, and more likely to be married or living with a partner than were HCMC participants. More racial/ethnic minorities were represented in the HCMC sample (89\%) than in the Mayo Clinic sample (3\%). Median number of self-reported health conditions for both samples was five.

Twenty-five patients participated in one of four focus groups (five to eight participants per group). Two Mayo Clinic groups consisted of patients from diabetes and heart failure patient advocacy groups $(\mathrm{n}=12$; age range, 52-87 years; $42 \%$ female; $0 \%$ non-white). Two HCMC groups consisted of patients from cardiology and renal failure clinics $(n=13$; age range, 47-70 years; $46 \%$ female; $69 \%$ non-white). Median number of self-reported health conditions for the focus group participants was three (range, 1-6 conditions).

\section{Interview results}

A full description of the results of the first 32 interviews conducted at the Mayo Clinic, along with representative patient quotes, can be found in Eton et al. ${ }^{18}$ Findings from these interviews led to the derivation of a preliminary conceptual framework of burden of treatment (Figure 1). Briefly, the following three broad themes were identified: 1) the work patients must do to care for their health (eg, self-management activities, maintaining medical appointments); 2) problemfocused strategies that facilitate the work of medical self-care (eg, organizing and preparing medications, enlisting support from others); and 3) factors that exacerbate perceived treatment burden (eg, challenges with taking medication, emotional problems with others, role and social activity
Table I Characteristics of interviewees $(\mathrm{N}=50)$

\begin{tabular}{|c|c|c|}
\hline & $\begin{array}{l}\text { Mayo Clinic } \\
(\mathrm{N}=32)\end{array}$ & $\begin{array}{l}\text { Hennepin } \\
\text { County Medical } \\
\text { Center }(\mathrm{N}=18)\end{array}$ \\
\hline \multicolumn{3}{|l|}{ Age, years } \\
\hline Median & 59.5 & 50.5 \\
\hline Range & 26 to 85 & 25 to 61 \\
\hline \multicolumn{3}{|l|}{ Sex } \\
\hline Female & $20(63 \%)$ & $9(50 \%)$ \\
\hline Male & $12(38 \%)$ & $9(50 \%)$ \\
\hline \multicolumn{3}{|l|}{ Race } \\
\hline White & 31 (97\%) & $2(11 \%)$ \\
\hline African-American & I (3\%) & $13(72 \%)$ \\
\hline Native American & 0 & $2(11 \%)$ \\
\hline Mixed (African/ & 0 & I (6\%) \\
\hline Native American) & & \\
\hline \multicolumn{3}{|l|}{ Education } \\
\hline $\begin{array}{l}\text { High school } \\
\text { graduate or less }\end{array}$ & $5(16 \%)$ & $12(67 \%)$ \\
\hline $\begin{array}{l}\text { Some college/ } \\
\text { technical degree }\end{array}$ & II (34\%) & $6(33 \%)$ \\
\hline College graduate & $16(50 \%)$ & 0 \\
\hline \multicolumn{3}{|l|}{ Marital status } \\
\hline $\begin{array}{l}\text { Married or living } \\
\text { with partner }\end{array}$ & $22(69 \%)$ & $4(22 \%)$ \\
\hline Not married & $10(31 \%)$ & 14 (78\%) \\
\hline \multicolumn{3}{|l|}{ Employment status } \\
\hline Retired/unemployed & 13 (4 |\%) & $5(28 \%)$ \\
\hline Full-time employed & $10(31 \%)$ & $2(11 \%)$ \\
\hline Part-time employed & $4(13 \%)$ & $2(11 \%)$ \\
\hline On disability or leave & $4(13 \%)$ & $8(44 \%)$ \\
\hline Homemaker & I (3\%) & I (6\%) \\
\hline \multicolumn{3}{|c|}{ Self-reported health conditions } \\
\hline Median & 5 & 5 \\
\hline Range & 1 to 16 & 3 to 8 \\
\hline \multirow[t]{11}{*}{$\begin{array}{l}\text { Top ten most reported } \\
\text { health conditions }\end{array}$} & $\begin{array}{l}\text { Gastrointestinal } \\
\text { problems (15) }\end{array}$ & $\begin{array}{l}\text { Hypertension } \\
\text { (I4) }\end{array}$ \\
\hline & Hypertension (14) & $\begin{array}{l}\text { Depression or } \\
\text { anxiety (II) }\end{array}$ \\
\hline & $\begin{array}{l}\text { Arthritis/joint } \\
\text { pain (I3) }\end{array}$ & $\begin{array}{l}\text { Arthritis/joint } \\
\text { pain (8) }\end{array}$ \\
\hline & Diabetes (I2) & $\begin{array}{l}\text { Back/neck } \\
\text { problems (7) }\end{array}$ \\
\hline & $\begin{array}{l}\text { Cardiovascular } \\
\text { disease }(10)\end{array}$ & Diabetes (7) \\
\hline & Depression (10) & $\begin{array}{l}\text { Asthma/ } \\
\text { COPD (7) }\end{array}$ \\
\hline & Hyperlipidemia (8) & Obesity (6) \\
\hline & Back/neck & Drugs/alcohol/ \\
\hline & problems (8) & smoking (5) \\
\hline & Eye problems (8) & $\begin{array}{l}\text { Cardiovascular } \\
\text { disease (3) }\end{array}$ \\
\hline & $\begin{array}{l}\text { Sleeping } \\
\text { problems (7) }\end{array}$ & $\begin{array}{l}\text { Other mental } \\
\text { health, sleep } \\
\text { disorders, chronic } \\
\text { pain, or migraine } \\
\text { headache (2) }\end{array}$ \\
\hline
\end{tabular}

Note: Copyright $\odot$ 2012. Dove Medical Press. Reproduced from Ridgeway JL, Egginton $J$ S, Tiedje K, et al. Factors that lessen the burden of treatment in complex patients with chronic conditions: a qualitative study. Patient Pref Adherence. 20I4;8:339-35I. ${ }^{20}$ Abbreviation: COPD, chronic obstructive pulmonary disease. 
limitations, financial challenges, confusion about medical information, and systemic obstacles encountered in health care delivery).

This version of the framework was considered preliminary, as it was derived using input from patients recruited from a single center and program. Moreover, we felt that the lack of socioeconomic and racial/ethnic diversity in the Mayo Clinic sample ( $84 \%$ college-educated; $97 \%$ white) was a limitation; hence, we included the additional 18 interviews of patients from the HCMC's primary care outpatient clinic. Collectively, these patients provided numerous illustrations of the major themes and subthemes outlined in the preliminary framework. All 18 patients (100\%) spoke of needing to do multiple things to manage their conditions, such as taking medications, maintaining medical appointments, monitoring health status, dieting, exercising, and participating in physical therapy. Sixteen patients $(89 \%)$ reported the use of one or more strategies to facilitate their self-care, the most frequent activity being organizing and preparing medications (61\%). Finally, seventeen patients $(94 \%)$ identified at least one factor that seemed to exacerbate felt burden, with the most frequently reported factors being systemic obstacles of health care delivery, ie, problems with individual providers or the health care system in general (72\%), and financial challenges (72\%).

A few new issues emerged from these interviews that were not apparent in the earlier interviews. Two of these issues were unique, and therefore required augmentation of the framework. Codes were therefore added to identify various "barriers to self-care" as well as perceived "physical and mental exhaustion due to self-care". Both of these were initially added as subthemes of the major theme, "factors that exacerbate felt burden". Patients reported on barriers to specific self-care activities, such as diet and exercise. For example, some patients spoke of reduced access to healthy foods, cravings making it difficult to maintain a healthy diet, or family members preparing less healthy foods:

See right now, I'm living in a shelter, so I just basically eat what they give me. [29-year-old African-American male]

And they (health care providers) say, "Eat more fruits." I'm just not a fruit person. I have a problem with meat. I love meat, any and all kind of meat. [55-year-old African-American female]

Interviewer: "Are there other things that make it hard to eat healthy foods?" Interviewee: "Yeah, it's just a craving for salty foods." [43-year-old Native American female]

It didn't start happening until I moved up here to live with my auntie ... I had to be real careful, because it's just like pork every day ... my auntie buy a lot of stuff - ice cream, all kinds of stuff, sweets, cakes, and she makes cakes ... you're kind of looking at that stuff, it's kind of tempting. [48-year-old African-American male]

Some patients found it difficult to engage in recommended exercise because of physical limitations or other priorities in their life:

Yeah, they (health care providers) tell me to try exercise or walking. But sometimes, I'll be walking, and I be having pain in my legs. [38-year-old African-American male]

Interviewer: "How often would you say you exercise a week?" Interviewee: "At least twice a week. They (health care providers) would like more, but that's all I can commit to right now ... Because I'm always tired ... I have a full plate at home. My husband has a bad heart. I have a daughter with cerebral palsy ... I don't have time to do all the other things ... sometimes I just forget about myself. [45-year-old African-American female]

Lack of reliable transportation was a barrier for some in getting to medical appointments:

I don't drive, I catch the bus. This morning I had a problem with the bus being late, so that made me late. [58-year-old African-American female]

I don't drive, and there was no bus schedule and I didn't have the money to buy the card for the bus ... So if I wasn't walking, I wasn't going ... so for a while, I wasn't even coming to the doctor. [53-year-old African-American female]

Finally, several patients spoke of a sense of physical and/or mental exhaustion with self-care, using terms like "overwhelmed", "depressed", "angry", and "worn out" to describe the monotony of self-care work:

... It's just that sometimes it can be overwhelming, and that's when the stress comes, that's when the anxiety comes, and that's when the depression comes. [44-year-old African-American male]

Some days, I just feel like I could just cry. I'll be like, "I'm so tired of being sick." ... I'm tired of medicine. Whatever I need to do to get off this medicine, I'm going to do. You just get fed up. [45-year-old African-American female]

It's emotionally difficult getting up, following the daily routines ... you know you need that medicine, but sometimes you feel like I am just so tired of taking medications every day. [55-year-old African-American female] 
Interviewer: "For some people, the work of caring for their health can be emotionally challenging. Is that true for you?" Interviewee: "Uh-hum, yeah. I get really stressed out. I feel a lot of hopelessness. Angry, just feel anger. Cry ... I know I cry sometimes. [44-year-old Native American female]

Upon completing the coding, the preliminary framework (Figure 1) and newly emergent issues from the HCMC patient interviews were reviewed. Modifications to the preliminary framework were made to accommodate new information learned in the second set of interviews and to further specify the construct of treatment burden. First, the "problem-focused strategies" were removed from the framework defining treatment burden, because these strategies describe voluntary activities that a person may choose to undertake to make self-care easier rather than non-voluntary self-care activities that patients are obligated to perform. These strategies are better construed as factors that may lessen perceived treatment burden. For more detail on these factors, see Ridgeway et al. ${ }^{20}$ Second, the subthemes describing "role and social activity limitations" and "physical and mental exhaustion of self-care" were rearranged into a new major theme entitled, "impacts of burden" as both appear to reflect outcomes of the demands of self-care. Third, the subtheme "systemic obstacles of health care delivery" - within the major theme "factors that exacerbate felt burden" - was further separated into two subthemes, one identifying obstacles associated with individual providers (eg, poor communication, lack of trust) and the other identifying obstacles associated with the health care system (eg, lack of care coordination, lack of care continuity, long wait times). The revised conceptual framework features three major themes: 1) "the work patients must do to care for their health"; 2) "challenges/stressors that exacerbate felt burden"; and 3) "impacts of burden". These themes and the subthemes associated with them are shown in Figure 2.

\section{Focus group results}

The focus groups were used to confirm the themes and subthemes that emerged from the interviews and to determine whether thematic content had been saturated. Saturation occurs when further qualitative inquiry yields similar thematic content to previous qualitative inquiries, ie, no new content is emerging. ${ }^{19}$ Table 2 diagrams a saturation grid of the themes and subthemes that were identified in the semistructured interviews. The body of the table indicates the focus groups in which these themes and subthemes were observed. As evidenced in the table, almost all of the thematic content from the interviews was observed across all four groups. All three of the major themes seen in the interviews were observed in all of the groups. Only one subtheme, "use of medical devices or equipment", was not mentioned by

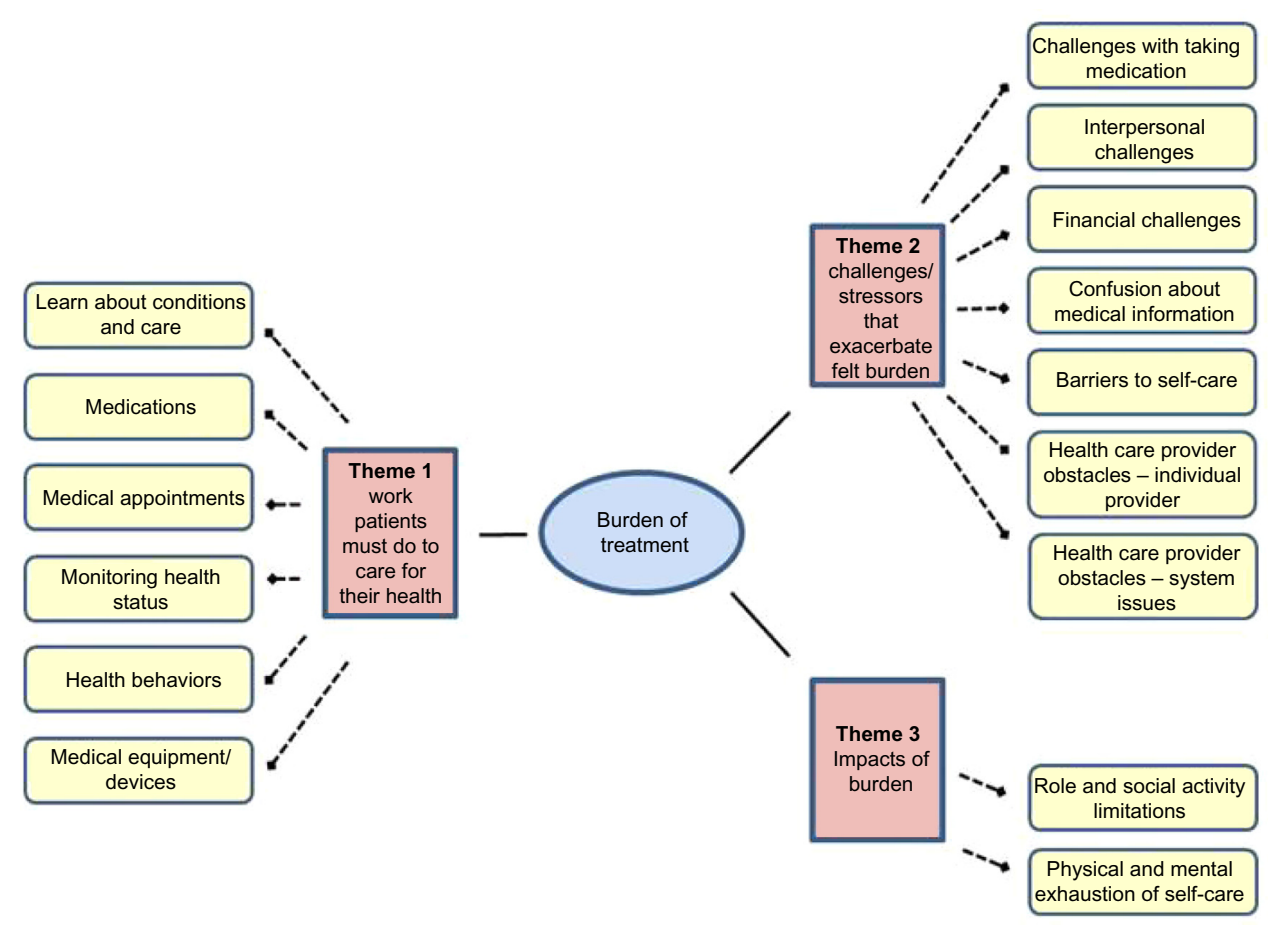

Figure $2 \mathrm{~A}$ final conceptual measurement framework of burden of treatment. 
Table 2 Saturation grid of themes and subthemes represented in focus groups

\begin{tabular}{|c|c|c|c|c|}
\hline \multirow[t]{2}{*}{ Themes and subthemes } & \multicolumn{2}{|c|}{ Mayo Clinic focus groups } & \multicolumn{2}{|c|}{$\begin{array}{l}\text { Hennepin County Medical } \\
\text { Center focus groups }\end{array}$} \\
\hline & $\begin{array}{l}\text { Group I } \\
(n=5)\end{array}$ & $\begin{array}{l}\text { Group } 2 \\
(n=7)\end{array}$ & $\begin{array}{l}\text { Group } 3 \\
(n=8)\end{array}$ & $\begin{array}{l}\text { Group } 4 \\
(n=5)\end{array}$ \\
\hline Theme I: work patients must do to care for their health & $x$ & $x$ & $x$ & $x$ \\
\hline - Learn about conditions and care & $x$ & $x$ & $x$ & $x$ \\
\hline - Taking medications & $x$ & $x$ & $x$ & $x$ \\
\hline - Medical appointments & $x$ & $x$ & $x$ & $x$ \\
\hline - Monitoring health & $x$ & $x$ & $x$ & $x$ \\
\hline - Health behaviors & $x$ & $x$ & $x$ & $x$ \\
\hline - Medical equipment/devices & $x$ & & & \\
\hline Theme 2: challenges/stressors that exacerbate felt burden & $x$ & $x$ & $x$ & $x$ \\
\hline - Challenges with taking medication & $x$ & $x$ & $x$ & $x$ \\
\hline - Interpersonal challenges & $x$ & $x$ & $x$ & $x$ \\
\hline - Financial challenges & $x$ & $x$ & $x$ & $x$ \\
\hline - Confusion about medical information & $x$ & $x$ & $x$ & $x$ \\
\hline - Barriers to self-care & $x$ & $x$ & $x$ & $x$ \\
\hline - Health care provider obstacles (individual provider) & $x$ & $x$ & $x$ & $x$ \\
\hline - Health care provider obstacles (system issues) & $x$ & $x$ & $x$ & $x$ \\
\hline Theme 3: impacts of burden & $x$ & $x$ & $x$ & $x$ \\
\hline - Role/social activity limitations & $x$ & $x$ & $x$ & $x$ \\
\hline - Physical/mental exhaustion of self-care & $x$ & $x$ & $x$ & $x$ \\
\hline
\end{tabular}

Note: $x$ indicates theme observed.

patients in every group. Furthermore, no new themes emerged in the focus groups. Hence, content saturation appears to have been adequately demonstrated. Given that the issues represented in the revised conceptual framework (Figure 2) were verified by narrative descriptions in the groups, we consider this framework to be a good approximation of what treatment burden likely means to patients with MCCs.

\section{Discussion}

In this qualitative study, we developed, refined, and tested a conceptual framework of treatment burden in a diverse sample of people experiencing complex self-management. The final framework is comprised of three major themes, including 1) the work patients must do to care for their health, 2) the challenges/stressors that exacerbate felt burden, and 3) the impacts of burden. These themes and their associated subthemes were confirmed in focus groups, with thematic saturation suggesting that the final framework does indeed capture key aspects of treatment burden from the patient perspective. The results demonstrate the importance of including diverse samples in the early stages of instrument development and concept refinement.

Albeit rich, the data that inform the conceptual framework are derived from qualitative inquiries with relatively small samples of patients. To verify the robustness of the framework, it is helpful to compare the results to other analyses. Our research team recently conducted a review of PRMs of treatment burden in three chronic diseases (diabetes, kidney disease, and heart failure) with the goal of identifying common content domains (domains shared by multiple PRMs that cut across disease types). ${ }^{25}$ From 98 included studies, 57 PRMs were identified across the diseases. Twelve common content domains were identified. These domains are indicated in Table 3, along with a conceptual mapping of the domains onto the major themes of our final framework. As shown in Table 3, the indicated PRM domains show reasonable overlap with the themes articulated in the conceptual framework of the current study, lending support to its content validity.

Table 3 Common content domains from disease-specific, patient-reported measures of treatment burden mapped onto the final conceptual framework themes

\begin{tabular}{ll}
\hline Common content domains (12) & Framework theme (3) \\
\hline - Treatment convenience & $\begin{array}{l}\text { Theme I: work patients must } \\
\text { - Self-care convenience }\end{array}$ \\
- Monitoring burden & \\
- Diet/food-related issues & \\
- Medical device bother & \\
- Medication side-effects & Theme 2: challenges/stressors \\
- Family conflict & that exacerbate burden \\
- Economic burden & \\
- Scheduling flexibility & \\
- Lifestyle impact (role and social) & Theme 3: impacts of burden \\
- Emotional/regimen distress & \\
- Overall treatment burden & \\
\hline
\end{tabular}


It is also instructive to compare our findings to those of others independently pursuing conceptualization of treatment burden. We are encouraged by the similarity of our findings to those of Sav et al in Australia. ${ }^{26,27}$ In a concept analysis of prior studies, they too have indicated that treatment burden is a multi-dimensional construct. ${ }^{27}$ Furthermore, after interviewing a culturally and linguistically diverse sample of 97 people touched by the diagnosis of a chronic condition(s) (including patient-consumers and unpaid caregivers), Sav et $\mathrm{al}^{26}$ found that treatment burden consists of the following four inter-related components: financial burden, time and travel burden, medication burden, and health care access burden. Each of these components appears to map themes represented in our conceptual framework. Financial burden (ie, costs of medications and consultations) were reflected in our "financial challenges" subtheme. Burdens associated with the time invested in self-care were also implicit in many subthemes of our framework, including "challenges with taking medication", "medical appointments", "monitoring health", "health behaviors", "role/social activity limitations", and "physical/mental exhaustion of self-care". We identified travel burden as a "barrier to self-care" specifically, as it relates to getting to and from medical appointments. Medication burdens (eg, side effects and inconvenience of taking multiple medications) were represented in our "challenges with taking medication" subtheme. Finally, health care access burdens resulting from unhelpful relationships with individual providers or systemic obstacles, such as lack of care continuity and care coordination, were represented in our framework as "individual provider obstacles" and "health care system issues", respectively.

Our conceptual framework fits with another recent theoretical conceptualization of treatment burden and we believe will provide a pragmatic means of operationalizing the construct in future tests and measurement models. May et al recently articulated "burden of treatment theory" as a structural model focused on the routine "work" that patients and their networks must do to treat and manage chronic health conditions. ${ }^{28}$ For many people today this means managing MCCs. ${ }^{29-31}$ As May et al ${ }^{28}$ point out, "the business of being sick" requires that the patient (and their social network) must accomplish a wide range of tasks delegated to them by the health care system. The ability and ease with which they can engage in these tasks (ie, their "capacity") determines whether the "work" will be perceived as manageable and routine or unmanageable and excessively burdensome. Our conceptual framework codifies many of the general tasks of treatment and self-care (ie, the "work") as well as barriers to accomplishing these tasks that might reduce a person's capacity to respond to the demands. We have elected to separate a host of personal, social, and health care resources that may serve to enhance capacity ${ }^{20}$ from the framework of treatment burden per se, for conceptual simplicity and practicality. The principal purpose of the framework is to inform a measurement instrument of manageable size and complexity. However, this distinction is not meant to infer that the concepts of workload and capacity are orthogonal. Burden of treatment theory teaches us that the two concepts are, in fact, connected and interdependent. ${ }^{28}$

\section{Limitations}

This study has a few limitations. As previously indicated, there are limits to generalizing qualitative findings from relatively small samples. However, we are encouraged by the consistency of our findings to those of others, ${ }^{26,27}$ as well as the conceptual overlap of our framework with concepts observed across a host of disease-specific measures of treatment burden. ${ }^{25}$ Second, an inherent weakness in studying treatment burden is that the most burdened patients may simply not have the time or energy to participate in research studies. Several patients eligible for the study declined to participate, citing a lack of time. Third, we relied on patients to self-report their medical conditions. While medical record review might appear to provide data that are more objectively reliable, given the variability in provider coding of various conditions, we decided to let the patient indicate what conditions were most personally salient. Still, recall bias could have resulted in under- or over-reporting of conditions. Fourth, the study was undertaken in the United States and therefore, some of the issues of treatment burden may be unique to patients treated within the American health care system. Finally, our qualitative inquiries used patient input alone to inform the framework. It is possible that informal caregivers and health care providers may have different views on what is burdensome to the person for whom they care.

\section{Conclusion}

We have finalized a conceptual framework of a general burden of treatment construct using semi-structured interviews and focus groups with patients coping with MCCs (Figure 2). This model is currently being used to inform derivation of a multidimensional, self-report measure of this construct. A valid, comprehensive measure of treatment burden would have many potential uses. It could be used in research to assess outcome of programs designed to promote care coordination, such as medical homes. It could be used to help assess and compare the performance of established health care entities. Finally, measuring and reporting the key drivers of treatment burden for individual 
patients could promote meaningful dialogue between patients and their providers, including ways to reduce the burden and better align care plans to patient preferences.

\section{Acknowledgments}

The research reported in this publication was supported by the Sponsorship Research Board of St Mary's Hospital (Rochester, MN, USA); Mayo Clinic's Center for Translational Science Activities, through grant number UL1 RR024150 from the National Center for Research Resources, a component of the National Institutes of Health; and the National Institute of Nursing Research of the National Institutes of Health under award number R21NR012984.

\section{Disclosure}

The authors report no conflicts of interest in this work.

\section{References}

1. Graves MM, Adams CD, Bender JA, Simon S, Portnoy AJ. Volitional nonadherence in pediatric asthma: parental report of motivating factors. Curr Allergy Asthma Rep. 2007;7(6):427-432.

2. Haynes RB, McDonald HP, Garg AX. Helping patients follow prescribed treatment: clinical applications. JAMA. 2002;288(22):2880-2883.

3. Kunt T, Snoek FJ. Barriers to insulin initiation and intensification and how to overcome them. Int J Clin Pract Suppl. 2009;(164):6-10.

4. Vijan S, Hayward RA, Ronis DL, Hofer TP. Brief report: the burden of diabetes therapy: implications for the design of effective patient-centered treatment regimens. J Gen Intern Med. 2005;20(5):479-482.

5. Shah S, Akbari M, Vanga R, et al. Patient perception of treatment burden is high in celiac disease compared with other common conditions. Am $J$ Gastroenterol. 2014;109(9):1304-1311.

6. Ho PM, Rumsfeld JS, Masoudi FA, et al. Effect of medication nonadherence on hospitalization and mortality among patients with diabetes mellitus. Arch Intern Med. 2006;166(17):1836-1841.

7. Rasmussen JN, Chong A, Alter DA. Relationship between adherence to evidence-based pharmacotherapy and long-term mortality after acute myocardial infarction. JAMA. 2007;297(2):177-186.

8. Anderson RT, Skovlund SE, Marrero D, et al. Development and validation of the insulin treatment satisfaction questionnaire. Clin Ther. 2004;26(4):565-578.

9. Boyd CM, Wolff JL, Giovannetti E, et al. Healthcare task difficulty among older adults with multimorbidity. Med Care. 2014;52(Suppl 3): S118-S125.

10. Brod M, Hammer M, Christensen T, Lessard S, Bushnell DM Understanding and assessing the impact of treatment in diabetes: the Treatment-Related Impact Measures for Diabetes and Devices (TRIM-Diabetes and TRIM-Diabetes Device). Health Qual Life Outcomes. 2009;7:83.

11. Pifferi M, Bush A, Di Cicco M, et al. Health-related quality of life and unmet needs in patients with primary ciliary dyskinesia. Eur Respir J. 2010;35(4):787-794.

12. May C, Montori VM, Mair FS. We need minimally disruptive medicine BMJ. 2009;339:b2803.
13. Liu JY, Woloshin S, Laycock WS, Rothstein RI, Finlayson SR, Schwartz LM. Symptoms and treatment burden of gastroesophageal reflux disease: validating the GERD assessment scales. Arch Intern Med. 2004;164(18):2058-2064.

14. Sawicki GS, Sellers DE, Robinson WM. High treatment burden in adults with cystic fibrosis: challenges to disease self-management. J Cyst Fibros. 2009;8(2):91-96.

15. Anderson RT, Girman CJ, Pawaskar MD, et al. Diabetes Medication Satisfaction Tool: a focus on treatment regimens. Diabetes Care. 2009; 32(1):51-53.

16. Atkinson MJ, Sinha A, Hass SL, et al. Validation of a general measure of treatment satisfaction, the Treatment Satisfaction Questionnaire for Medication (TSQM), using a national panel study of chronic disease. Health Qual Life Outcomes. 2004;2:12.

17. Nordyke RJ, Chang CH, Chiou CF, Wallace JF, Yao B, Schwartzberg LS Validation of a patient satisfaction questionnaire for anemia treatment, the PSQ-An. Health Qual Life Outcomes. 2006;4:28.

18. Eton DT, Ramalho de Oliveira D, Egginton JS, et al. Building a measurement framework of burden of treatment in complex patients with chronic conditions: a qualitative study. Patient Relat Outcome Meas. 2012;3:39-49.

19. Brod M, Tesler LE, Christensen TL. Qualitative research and content validity: developing best practices based on science and experience. Qual Life Res. 2009;18(9):1263-1278.

20. Ridgeway JL, Egginton JS, Tiedje K, et al. Factors that lessen the burden of treatment in complex patients with chronic conditions: a qualitative study. Patient Pref Adherence. 2014;8:339-351.

21. Cowie MR, Zaphiriou A. Management of chronic heart failure. $B M J$ 2002;325(7361):422-425

22. Jansen DL, Grootendorst DC, Rijken M, et al; PREPARE-2 Study Group. Pre-dialysis patients' perceived autonomy, self-esteem and labor participation: associations with illness perceptions and treatment perceptions. A cross-sectional study. BMC Nephrol. 2010;11:35.

23. Ritchie J, Lewis J. Qualitative Research Practice: A Guide for Social Science Students and Researchers. London,UK: Sage; 2003.

24. Krueger RA, Casey MA. Focus Groups: A Practical Guide for Applied Research. 4th ed. Thousand Oaks, CA: Sage; 2009.

25. Eton DT, Elraiyah TA, Yost KJ, et al. A systematic review of patientreported measures of burden of treatment in three chronic diseases. Patient Relat Outcome Meas. 2013;4:7-20.

26. Sav A, Kendall E, McMillan SS, et al. 'You say treatment, I say hard work': treatment burden among people with chronic illness and their carers in Australia. Health Soc Care Community. 2013;21(6):665-674.

27. Sav A, King MA, Whitty JA, et al. Burden of treatment for chronic illness: a concept analysis and review of the literature. Health Expect. Epub January 31, 2013.

28. May CR, Eton DT, Boehmer K, et al. Rethinking the patient: using Burden of Treatment Theory to understand the changing dynamics of illness. BMC Health Serv Res. 2014;14:281

29. Centers for Medicare and Medicaid Services. Chronic Conditions Among Medicare Beneficiaries, Chartbook. 2012 ed. Baltimore, MD: 2012.

30. Freid VM, Bernstein AB, Bush MA. Multiple chronic conditions among adults aged 45 and over: trends over the past 10 years. NCHS Data Brief. 2012;(100):1-8.

31. Ward BW, Schiller JS. Prevalence of multiple chronic conditions among US adults: estimates from the National Health Interview Survey, 2010 Prev Chronic Dis. 2013;10:E65. 


\section{Publish your work in this journal}

Patient Related Outcome Measures is an international, peer-reviewed, open access journal focusing on treatment outcomes specifically relevant to patients. All aspects of patient care are addressed within the journal and practitioners from all disciplines are invited to submit their work as well as healthcare researchers and patient support groups.

The manuscript management system is completely online and includes a very quick and fair peer-review system. Visit http://www.dovepress. com/testimonials.php to read real quotes from published authors.

Submit your manuscript here: http://www.dovepress.com/patient-related-outcome-measures-journal 